\title{
Entoptic phenomena and reproducibility of corneal striae following contact lens wear
}

\author{
MURRAY H JOHNSON, C MONTAGUE RUBEN, AND DAVID M PERRIGIN \\ From the Institute for Contact Lens Research, University of Houston-University Park, 4901 Calhoun Road, \\ Houston, Texas 77004, USA
}

\begin{abstract}
SUMMARY Vertical corneal striae distributed across the posterior cornea are one of the objective signs of clinically unacceptable corneal swelling $(>6 \%)$ resulting from contact lens wear. This study reports that corneal striae are repeatable both in configuration and location with different levels of hypoxia. In most instances entoptic phenomena result from the presence of these lines. The results suggest that the healthy, avascular, transparent cornea has certain localised areas in its anatomical structure which may give rise to bundles of collagen fibres being made visible objectively and subjectively during conditions of corneal swelling.
\end{abstract}

Corneal striae is a term used to describe lines seen in the corneal stroma of varied appearance, aetiology, and pathology. Deep striae have been seen as a result of trauma (penetrating wounds), ${ }^{1}$ after intraocular operations (striate keratitis), ${ }^{\prime}$ in degenerative changes of collagen such as keratoconus, ${ }^{2-4}$ in diabetes, ${ }^{5}$ and in idiopathic ${ }^{6}$ corneal conditions. It is a well known clinical observation that vertical striate lines distributed across the posterior cornea are caused by corneal oedema accompanying hydrogel (soft) lens wear. ${ }^{78}$ The vertical or near-vertical striate lines, indicating the presence of 4 to $6 \%$ or more of corneal oedema, ${ }^{9}$ are reversible on removal of the lens. ${ }^{8}$ Striate keratopathy accompanies stromal swelling of about 7 to $10 \%$ or more, and appears as deep folds in the endothelial mosaic/Descemet's membrane area. ${ }^{78}$ The stromal lines can best be viewed against the dark background of the pupil with high light intensity from the slit-lamp biomicroscope by using direct focal illumination. ${ }^{6910}$

The reproducibility and entoptic phenomena of corneal striae were first noted by Johnson (reported by Johnson and Ruben") while investigating stromal oedema induced by soft gel lens wear. ${ }^{12}$ The striae were induced by thick hydrogel lenses in normal adult corneae following three hours of wear in both the open and closed eye conditions. Photographic records were made of the appearance of the striae by retroillumination, and the similarity to the entoptic phenomena as recorded in a drawing by the indi-

Correspondence to Dr Murray H Johnson. vidual was strikingly similar. Furthermore, there was intrasubject repeatability of striae with large intersubject variability of corneal striate lines.

In this paper we describe the repeatability and entoptic phenomena of corneal striae following contact lens wear and provide additional clues to its aetiology.

\section{Material and methods}

\section{SUBJECTS}

The study involved 11 volunteers with an age range of 23 to 36 years, consisting of nine males and two females. A second group of subjects seen after an interval of one year comprised five females and two males, with an age range of 21 to 30 years. All were free of any eye pathology and none had previously worn contact lenses.

To verify the first series of observations a second group of subjects similar to the first were studied. The experiment was to ascertain a qualitative finding and not measure in any degree the striae.

The illustrations (Figs. 1 and 2) are selected from those taken from one subject.

\section{CONTACT LENSES}

To induce corneal swelling greater than $6 \%$, thick hydrogel lenses were worn by each subject. The lenses used in this study were $38.6 \%$ water content hydrogels (Metrosoft II - polymacon) manufactured by Metrosoft Incorporated (Austin, Texas). Two lenses were used, each having a base curve of $8.3 \mathrm{~mm}$, 


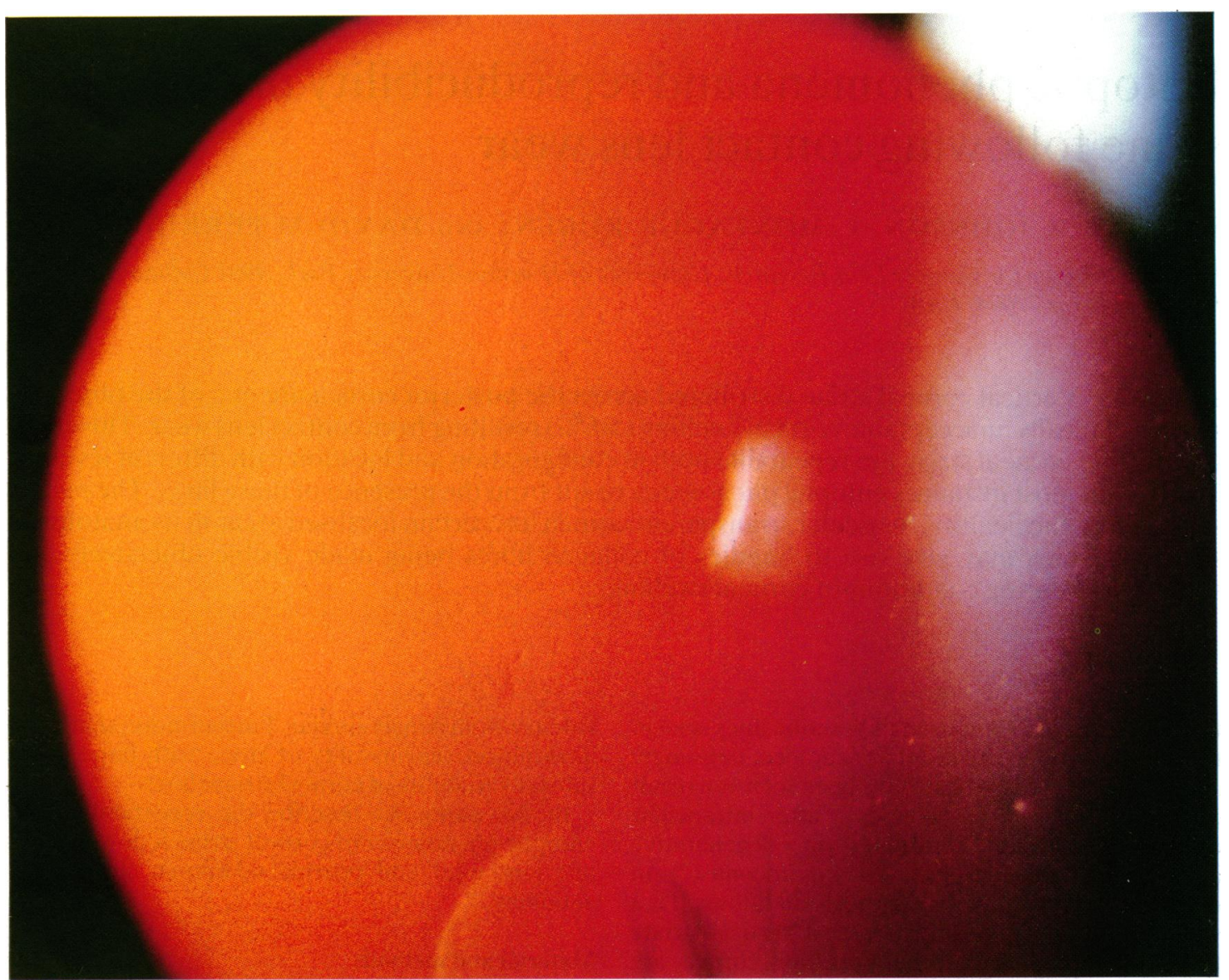

Fig. 1 Corneal oedema produced by having the subject wear a $0.5 \mathrm{~mm}$ thick HEMA lens for three hours (open eye). Corneal striae are present. The inferior round area that appears elevated is a large dimple caused by a trapped air bubble between the lens and cornea.

power of $-2.00 \mathrm{D}$, total diameter of $13.5 \mathrm{~mm}$, and thickness of $0.2 \mathrm{~mm}$ and $0.5 \mathrm{~mm}$. The $0.2 \mathrm{~mm}$ thick lens was worn in the closed eye and the $0.5 \mathrm{~mm}$ thick lens was worn in the open eye for three hours to show whether the striae were repeatable with different levels of hypoxia.

\section{PHOTOGRA PHY}

To achieve good slit-lamp photography of the striate lines the pupils were widely dilated, so that a wide area of the cornea could be photographed. The two methods used were direct focal illumination "1" and retroillumination from the fundus. The retroillumination method utilised an intense vertical parallelepiped beam, placed just inside the widely dilated pupil margin, thus illuminating the cornea by retroillumination from the fundus.
An adapter that allowed photography through the optical system of a Haag-Streit model 900 slit-lamp was used for the project. The camera body was a Nikon FE with an all ground glass focusing screen. The camera body was mounted to the slit-lamp eye piece with the adapter so that alignment and focusing were possible through the camera viewfinder. The camera was set on the automatic mode for the photography, and exposure time was thus determined by the camera's built-in meter.

The film used was Kodak Ektachrome (ISO 160) balanced for tungsten illumination.

The linear magnification produced by this system of photography was either $2 \cdot 2 \times$ or $3 \cdot 4 \times$ for all shots.

EXPERIMENTAL DESIGN AND PROCEDURE

The corneal swelling responses to the physiological 


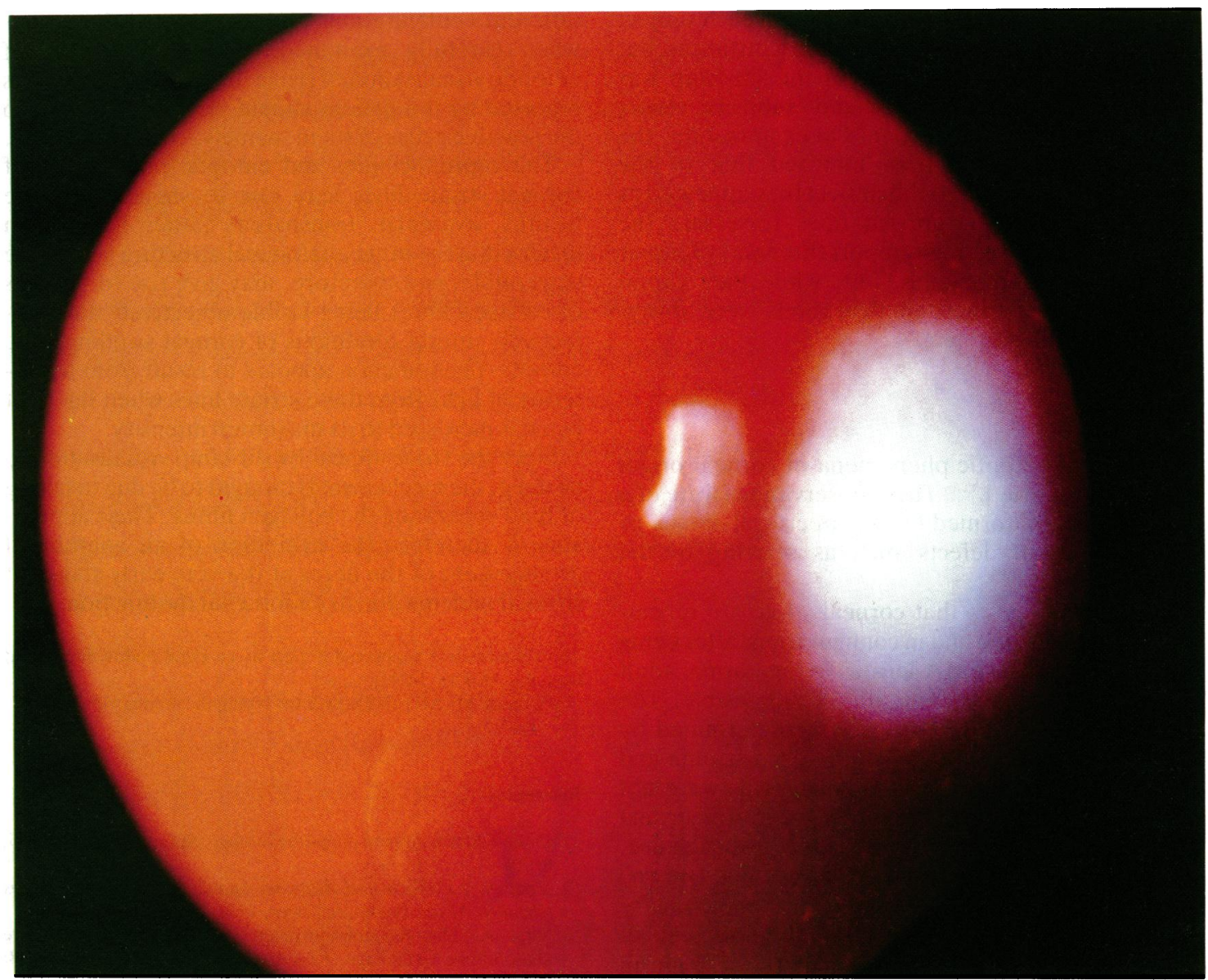

Fig. 2 Corneal oedema produced by having same subject as in Fig. 1 wear a $0.2 \mathrm{~mm}$ thick HEMA lens for three hours (closed eye). Corneal striae are present. Note that the location and configuration of these lines are the same as in Fig. 1.

stress of hypoxia created by the thick hydrogel lenses were determined by having each subject wear low water contact lenses $(38.6 \%)$ for three hours.

Three separate sessions of photography were held. During one the undisturbed cornea was photographed, and during the second and third the cornea was photographed after $(a)$ three hours of $0.5 \mathrm{~mm}$ thick lens wear (open eye) and (b) three hours of 0.2 $\mathrm{mm}$ thick lens wear (closed eye) respectively.

For the closed eye condition each subject wore a Coverlet adhesive eye occluder (ElastoplastBeiersdorf, Inc., Conn) over the eye with the contact lens; it was positioned to eliminate any undue pressure on the globe while the eye was kept closed. No more than one lens was worn in any one day. After two and one-half hours of wear the lenses were removed for pupillary dilatation. The lenses were reinserted five minutes after instillation of a mydri- atic for completion of the three-hour period. The drug was instilled at this time to ensure mydriasis, because an earlier pilot study had shown that instillation of the drug prior to lens wear did not ensure effective mydriasis after three hours.

To enable entoptic observation of the striae the illuminating arm of the slit-lamp was placed at an angle of $45^{\circ}$ to $50^{\circ}$ to the microscope with the beam intensity increased to its maximum. The subjects were then asked to describe the appearance of the striae lines and to remember their configurations. A careful slit-lamp examination of the cornea was then performed to determine the plane of the striae.

\section{Results}

Our results are photographically summarised in Figs. 1 and 2 . We noted that the location and configura- 
tions of these lines were the same within each subject but different between subjects. In most instances, but only when the beam intensity of the slit-lamp was increased to its maximum, did subjects report entoptic imagery of the striae. On examination, the configuration of the striae matched that of the subjects' description. To the subject they appeared as long or short, thin, greyish lines traversing the cornea. One subject might report three wavy lines or another five straight lines, but, while they varied between subjects, their configurations were always the same within a subject.

\section{Discussion}

Examples of entoptic phenomena of corneal origin have been reported..$^{13-16}$ These observations were of a 'groove pattern' formed by the superficial cornea or emanating from defects such as scarring of the corneal surface. ${ }^{17-19}$

This study reports that corneal striae are repeatable both in location and in configuration (after being induced by thick HEMA lenses) in the normal adult cornea, and that they are entoptically visible. The vertical or near-vertical striae were determined by slit-lamp examination to be in the deep stroma and Descemet's membrane. Endothelial folds were not observed. The collagen fibril in the posterior stroma is, as stated by Tripathi ${ }^{20}$ from histological evidence, to vary in diameter from 19 to $34 \mathrm{~nm}$ while Brown ${ }^{21}$ and later Sturrock ${ }^{6}$ estimated from photomacrographic methods that deep stromal striae seen in normal cornea were in the order of 18 to $22 \mathrm{~nm}$ in diameter. Thus there is close agreement between measurements taken from human cadaver specimens examined histologically with those seen and measured by optical methods. Sturrock's work ${ }^{6}$ on the normal non-oedematous cornea indicates that striae are seen adjacent to Descemet's membrane and best sighted by oblique illumination in the marginal zones of the cornea. In addition he found that the incidence of these striae lines was $85 \%$ in a series of 200 patients aged between 15 and 96 years. However, we could not detect striae in the undisturbed cornea.

The central deep striae appear to be visualisations of the collagen fibril, which is of higher refractive index than its surrounds, so that the fibrils become more visible entoptically. In addition these striae lines having a diameter of 18 to $22 \mu \mathrm{m}^{6}$ are very thin, resulting in light being scattered once it has traversed the cornea, which is then seen entoptically.

Are corneal striae lines 'fingerprints', or more appropriately 'cornea stromal prints'? Evidence from this study appear to suggest that indeed they may very well be. All subjects seen with striae had different configurations and locations of these lines when carefully examined. The phenomenon of entoptic visualisation of striae in contact lens wearers reported by the patient should alert the clinician to the possible cause of them, namely, corneal oedema.

The reproducibility and entoptic phenomena of corneal striate lines lead one to suggest that the healthy, avascular, transparent cornea has certain localised areas in its anatomical structure which are susceptible, and therefore, may give rise to bundles of collagen fibres being visible objectively and subjectively during conditions of corneal swelling. The entoptic phenomenon appears to result from a scattering of light from these striate lines when the light beam is increased to its maximum intensity.

Since the striae appear by slit-lamp visualisation to be deep, the mechanism is thought to be due to laking of fluid separating the collagen fibres. Their appearance is therefore the exhibition of an anatomical arrangement of the fibres at the very early stages of stromal oedema due to endothelial dysfunction.

This research was supported in part by an Ezell Fellowship award from the AOF (to MHJ).

We thank Ms Alvenia Daniels for typing the manuscript.

\section{References}

1 Duke-Elder S. System of ophthalmology. St Louis: Mosby, 1965; 8: 705-7.

2 Vogt A. Lehrbuch und Atlas der Spaltlampenmikroskopie des lebenden Auges. Berlin: Springer, 1930: 1.

3 Vogt A. Die Keratokonuslinien der Kegelspitze und ihre anatomische Grundlage. Klin Monatsbl Augenheilkd 1937; 98: 557-92 C.

4 Schmidt M. Die Natur und Entstehungsweise der Keratokonislinien. Klin Monatsbl Augenheilkd 1938; 101: 36-49.

5 Henkind P, Wise G. Descemet's wrinkles in diabetes. Am J Ophthalmol 1961; 52: 371-4.

6 Sturrock G. Glassy corneal striae. Graefes Arch Klin Exp Ophthalmol 1973; 188: 245-52.

7 Sarver MD. Striate corneal lines among patients wearing hydrophilic contact lenses. Am J Optom Physiol Opt 1971; 48: 762-3.

8 Polse KA, Mandell RB. Etiology of corneal striae accompanying hydrogel lens wear. Invest Ophthalmol Vis Sci 1976; 15: 553-6.

9 Kame R. Clinical management of hydrogel induced edema. Am J Optom Physiol Opt 1976; 53: 468-73.

10 Wechsler $\mathrm{S}$. Corneal striate lines and their value as a clinical diagnostic sign. Int Contact Lens Clin 1978; 5: 82-5.

11 Johnson $\mathrm{MH}$, Ruben $\mathrm{M}$. The reproducibility of corneal striae and its entoptic imagery. Am J Optom Physiol Opt 1983; 60: 68P (abstr).

12 Johnson MH, Boltz RL, Godio LB. An investigation of the predictability of corneal swelling. Am J Optom Physiol Opt 1983; 60: $12 \mathrm{P}$ (abstr)

13 Hirschberg J. Einfühurung in die Angenheilkunde. 2nd ed. Leipzig: Thieme, 1901: 96.

14 Helmholtz $\mathrm{H}$ von. Handbuch der physiologischen Optik. 3rd ed. Leipzig: Voss, 1909; 1: 151.

15 Esser AAM. Mikroskopie der eigenen Hornhaut. Klin Monatsbl Augenheilkd 1926; 76: 389-93.

16 Duke-Elder S. System of ophthalmology. St Louis: Mosby, 1962; 8: 449. 
17 Bron AJ. Anterior corneal mosaic. Br J Ophthalmol 1968; 52: 659-69.

18 Schweitzer NMJ. A fluorescein colored polygonal pattern in the human cornea. Arch Ophthalmol 1967; 77: 548-53.

19 Ruben M. Dic punctata der keratisis superficialis. Contactologia $1984 ; 1: 31-3$
20 Tripathi R. Applied physiology and anatomy. In: Ruben M, ed. Contact lens practice. London: Baillière Tindall, 1975: 38.

21 Brown N. Visibility of transparent objects in the eye by retroillumination. BrJ Ophthalmol 1971; 55: 517-24.

Accepted for publication 6 October 1986. 